Rapid Reviews COVID-19

\title{
Reviews of "Medical Costs \\ of Keeping the US Economy \\ Open During COVID-19"
}

Christine Eibner ${ }^{1}$, Raffaele Vardavas ${ }^{1}$, Mehdi Shiva ${ }^{2}$

${ }^{1}$ RAND, ${ }^{2}$ Blavatnik School of Government

Published on: Aug 19, 2020

DOI: $10.1162 / 2 \mathrm{e} 3983 f 5 . f 7964612$

License: Creative Commons Attribution 4.0 International License (CC-BY 4.0). 
To read the original manuscript, click the link above.

Summary of Reviews: A major benefit of this analysis is that it presents a credible,flexible model for estimating the costs of COVID-19, although models will require updating with valid evidence. Sufficient compliance with lockdown guidelines could substantially reduce the medical costs of COVID-19.

Reviewer 1 (Christine Eibner, Raffaele Vardavas) | प्र० $\square$

Reviewer 2 (Mehdi Shiva) |

$$
\begin{aligned}
& \text { RR:C19 Strength of Evidence Scale Key } \\
& \text { प्रमप = Misleading } \\
& \text { प्र००० = Not Informative } \\
& \text { प्रा पि = Potentially Informative }
\end{aligned}
$$

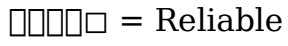

$$
\begin{aligned}
& \text { प्राप्र = Strong }
\end{aligned}
$$

To read the reviews, click the links below. 